\title{
Prediction of Response to Neoadjuvant Chemotherapy in Egyptian Patients with Locally Advanced Breast Cancer: The Evolving Role of Tumour Infiltrating Lymphocytes (TILs)
}

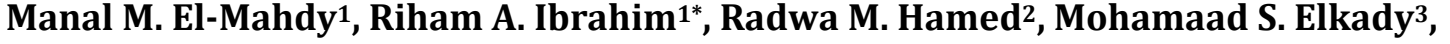 \\ Walid A. Bayoumy33, Zeinab M. Elsayed ${ }^{3}$, Mai M. Ezz-El-Din³ \\ ${ }^{1}$ Department of Pathology, Ain Shams University, Cairo, Egypt \\ ${ }^{2}$ International Medical Center, Cairo, Egypt \\ ${ }^{3}$ Department of Clinical Oncology, Faculty of Medicine, Ain Shams University, Cairo, Egypt \\ Email: ^dr_riham_ahmed@hotmail.com, manalmahdy69@gmail.com, radwahamed7@gmail.com, mselkady@hotmail.com, \\ Walid.bayoumy@gmail.com,z_hafeez@hotmail.com,Maiooyaz@yahoo.com
}

How to cite this paper: El-Mahdy, M.M., Ibrahim, R.A., Hamed, R.M., Elkady, M.S., Bayoumy, W.A., Elsayed, Z.M. and Ezz-ElDin, M.M. (2020) Prediction of Response to Neoadjuvant Chemotherapy in Egyptian Patients with Locally Advanced Breast Cancer: The Evolving Role of Tumour Infiltrating Lymphocytes (TILs). Journal of Cancer Therapy, 11, 206-219.

https://doi.org/10.4236/jct.2020.114018

Received: March 9, 2020

Accepted: April 19, 2020

Published: April 22, 2020

\section{Copyright $\odot 2020$ by author(s) and} Scientific Research Publishing Inc. This work is licensed under the Creative Commons Attribution International License (CC BY 4.0).

http://creativecommons.org/licenses/by/4.0/

\section{(c) (i) Open Access}

\begin{abstract}
Background \& objectives: Presence of TILs in breast cancer indicates better therapeutic responses to neoadjuvant chemotherapy (NAC), increased pCR and improved outcome. We aim at evaluation of TILs in breast cancer biopsies in correlation with pathological response after NAC in locally advanced breast cancer Methods. This study was conducted at Ain Shams university hospital and Maadi Military hospital in Egypt. 45 Female patients with locally advanced breast cancer were treated with NAC; pathological response was assessed. Tumours were categorized into: luminal A, luminal B, Her2 enriched and TNBC. Assessment of TILs (CD4 and CD8 lymphocytes) was based on Immuno-Oncology Biomarker Working Group guidelines. Results: Tumours were classified into high and low TIL groups using the interquartile range cutoff $(29 \%)$. High CD4 group showed increased pCR $(\mathrm{p}=0.003)$ and smaller residual tumours $(\mathrm{p}=0.04)$. High CD8 group showed a significant association with smaller residual tumours $(\mathrm{p}=0.003)$. At follow-up of 24-months, CD4 and CD8 high groups showed significantly higher 2-years DFS. The difference between CD4 high and low groups was significant in regards to estrogen receptor status, showing higher levels in hormone-negative tumors $(\mathrm{p}=0.029)$. Patients with Her2 subtype showed higher CD4 $(\mathrm{p}=$ 0.007) and CD8 expression ( $p=0.018)$. In CD4 \& CD8 low groups, more patients developed local recurrence and distant metastasis $(\mathrm{p}=0.025)$. Conclusion: We concluded that TILs may predict response to NAC and overall prognosis of breast cancer. The evaluation of TILs in correlation with mor-
\end{abstract}


phological or genomics-based parameters helps to stratify patients of breast cancer.

\section{Keywords}

Breast, Cancer, Lymphocytes, Neoadjuvant, Chemotherapy

\section{Introduction}

Neoadjuvant chemotherapy is increasingly used for the treatment of breast cancer aiming at reduction of the tumor size, allowing conservative surgical resection, eliminating clinically silent metastatic foci, and providing prognostic data based on the pathologic response of the tumor [1].

Evidence is emerging that pathological response after neoadjuvant chemotherapy, represented by total or near total destruction of the tumor in the surgical specimen, is believed to be a strong predictor for survival and an indicator of favourable overall prognosis [2].

The tumorigenesis of breast cancer is determined by genetic alterations, phenotypic variations of cancer cells and interaction between the tumor cells and the surrounding microenvironment. As important components of tumor microenvironment, tumor-infiltrating lymphocytes (TILs) are a group of mononuclear cells representing the immunological response to tumors [3]. Although breast cancer was not considered as a typical immunogenic disease, the morphological evaluation of TILs in breast cancer and their clinical relevance has become a focus of interest over the past few years. TILs are mostly comprised of $\mathrm{T}$ cells, followed by macrophages, B cells, natural killer and other immune cells. Immunohistochemistry (IHC) allows the identification of the different populations of TILs, by using specific markers of leukocytes [4] [5] [6].

Studies have indicated that presence of TILs is associated with improved therapeutic responses to chemotherapy in both neoadjuvant and adjuvant settings [7] [8]. Nevertheless, many trials have shown that TILs are associated with improved outcome of breast cancer patients; this could be reflected by the higher pathological complete response (pCR) rates in immune-rich cancers [9] [10]. These evidences support the fact that the efficacy of many cancer therapies relies upon establishing effective immunologic biomarkers within the microenvironment [11] [12] [13].

In this study we aim at evaluation of TILs (CD4 and CD8 T-lymphocytes) in breast cancer tissue biopsies and their correlation with the pathological response after neoadjuvant chemotherapy in Egyptian female patients with locally advanced breast cancer.

\section{Material and Methods}

\section{Patient Background:}

This is a prospective, single arm, clinical study conducted at Clinical Oncol- 
ogy and Nuclear Medicine Department Ain Shams University Hospital and Maadi Military Hospital in Egypt during the period from December 2015 to February 2018. A total of 45 female patients with locally advanced breast cancer (cT3N1, cN2, N3 or cT3, cT4 any N) were treated with neoadjuvant chemotherapy. Written, informed consent was obtained from all patients and the study was approved by the Research Ethics Committee (EC), Faculty of Medicine, Ain Shams University.

We included pre- or post-menopausal female patients with locally advanced breast cancer showing no evidence of metastatic disease. Male patients and patients with bilateral breast cancer were excluded. Cases subjected to primary surgical treatment were not included in this cohort.

Clinical evaluation, histopathologic assessment and treatment:

Breast cancer diagnosis was confirmed by histopathologic assessment of core needle biopsy and staged by systemic imaging studies using Computed Tomography (CT), ultrasonography (US) and bone scan. Tumors were evaluated for the immunohistochemical expression of estrogen receptors (ER), progesterone receptors (PR), HER2-neu and Ki-67 index. For cases of HER2-neu score 2, silver in-situ hybridization (SISH) was used for confirmation of the final score. Based on their immunohistochemical expression profiles, all tumors were categorized into four immunophenotypes: luminal A (ER+ and/or PR+, HER2-, Ki67-low); luminal B (ER+ and/or PR+, HER2+) (ER+ and/or PR+, Her2-, Ki67-high), Her2 enriched (ER-, PR-, Her2+); and TNBC (negative for ER, PR, and Her2). Luminal A and luminal B cases were collectively categorized as hormone receptor-positive breast cancers.

All patients received a neoadjuvant chemotherapy protocol comprised of Flurouracil (500 mg/m²/21days), Epirubicin (100 mg/m²/21days) and Cyclophosphamide $\left(500 \mathrm{mg} / \mathrm{m}^{2} / 21\right.$ days), for three or four cycles, followed by Docetaxel ( $75-100 \mathrm{mg} / \mathrm{m}^{2} / 21$ days) for three or four cycles. This was followed by radical surgery according to response, radiotherapy and hormonal treatment in hormone-positive cases. The pathologic effect of the neoadjuvant chemotherapy was assessed in all resected tumors. pCR was defined as the complete disappearance of all invasive tumor cells from breast tissue and regional lymph nodes regardless of the presence of residual ductal carcinoma in situ, according to Miller-Payne grading system [14]. Disease free survival (DFS) and overall survival (OS) were estimated over a follow-up period of two years.

\section{Evaluation of TILs:}

Formalin fixed paraffin embedded sections from all tumors were examined to identify the areas with dense lymphocytic infiltration. Immunohistochemical staining was performed using the T-cell markers CD4 (EP204) rabbit monoclonal antibody (RabMAb), and CD8 (C8/144B) mouse monoclonal antibody (Sigma-Aldrich) through an avidin-biotin-peroxidase complex method with diaminobenzidine as chromogen according to the manufacturer's instructions.

Assessment of stromal TILs was done using criteria described by Salgado et al. [15]. TILs were defined as the infiltrating lymphocytes within tumor stroma and 
expressed as the percentage of tumor area that was occupied by inflammatory (CD4 and CD8) cells. TILs were scored as continuous variables with a positivity cut off set at $1 \%$ [16].

The stromal lymphocytes were counted in three high power fields (magnification, $\times 400$ ). The counts were performed in areas of maximum lymphocytic infiltration. Foci demonstrating haemorrhage, necrosis, in situ carcinoma and crush artefacts were avoided. CD4 and CD8 lymphocytes expression levels were classified as either high and low based on values $\geq$ or $<$ the inter-quartile range (IQR) of each, respectively. The TILs evaluation was performed by two pathologists who were blinded to clinical data [4] [17] [18].

\section{Statistical Analysis}

SPSS package (version 22.0) was used for data analysis. The association between clinical and pathologic parameters were tested with $\chi^{2}$ test. Numerical data were expressed as mean and standard deviation or median and range as appropriate. Qualitative data were expressed as frequency and percentage. Chi-square test (Fisher's exact test) was used to examine the relation between qualitative variables. For quantitative data, comparison between two groups was done using either student $\mathrm{t}$-test or Mann-Whitney test (non-parametric t-test). Disease free survival (DFS) and overall survival (OS) will be estimated using Kaplan-Meier method.

\section{Results}

\section{Patient demographics and clinical characteristics:}

Patient age ranged between 33 and 66 with median age 53 years. Most of patients were older than 35 years old (93\%). Premenopausal females were 21 patients $(46 \%)$ while postmenopausal were $24(53 \%)$. Tumor characteristics are summarized in (Table 1).

Pathologic response to treatment:

After or during neoadjuvant chemotherapy, 13 (28.9\%) patients developed pCR, 25 (55.6\%) showed evidence of partial remission in the form of residual invasive tumor, 4 (8.9\%) had stationary disease and $3(6.6 \%)$ patients showed tumor progression during chemotherapy.

Tumor infiltrating lymphocytes (TIL) analysis:

Among our cases, 40 (88.8\%) tumors showed positive staining for CD4, and 5 (11\%) were negative. The results were slightly different for CD8, as $44(97.7 \%)$ tumors were positive and only $1(0.2 \%)$ tumor was negative (Figure 1 ).

All tumors were classified into high and low TIL groups using the interquartile range (IQR). Cases showing levels equal to or higher than the IQR were included in the TILs high group, while TILs low group included cases expressing TILs levels lower than the IQR value.

In the overall cohort, the interquartile range (IQR) for both CD4 and CD8 was $30 \%(0 \%-60.0 \%)$ (Figure 2). The CD4 low and high groups included 36 and 9 cases respectively, while CD8 low and high groups included 38 and 7 cases. 


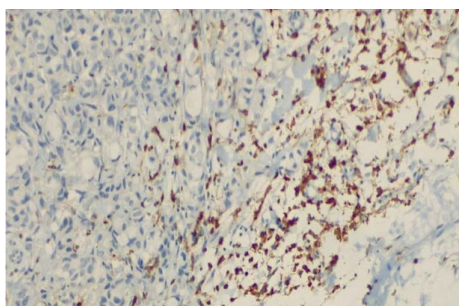

(a)

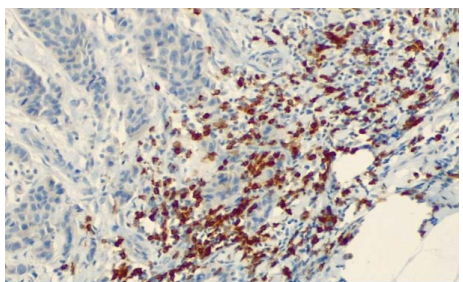

(c)

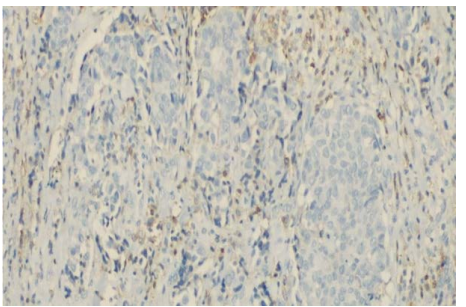

(b)

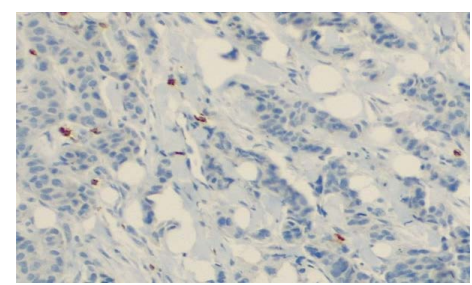

(d)

Figure 1. Representative image of a breast cancer tissue biopsy with CD4 and CD8 TIL immunostaining ( $\times 400)$. (a) high CD4 infiltration within the border of an invasive tumor, (b) low CD4 infiltration, (c) high CD4 infiltration within the border of an invasive tumor, (d) low CD8 infiltration.

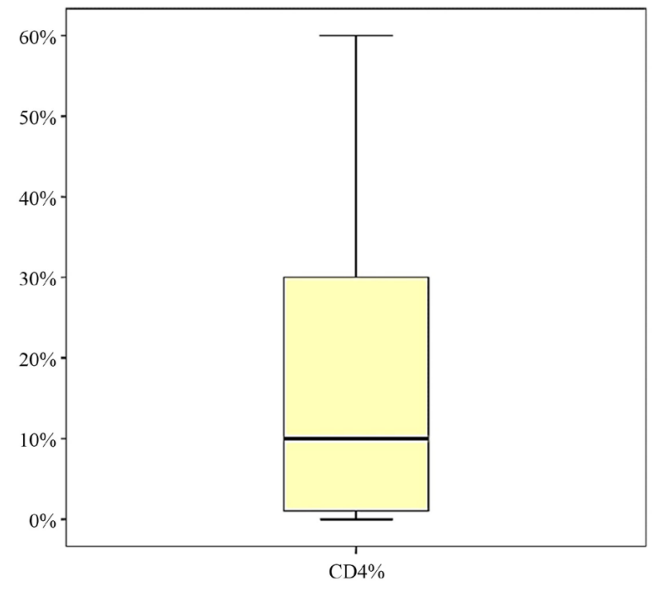

(a)

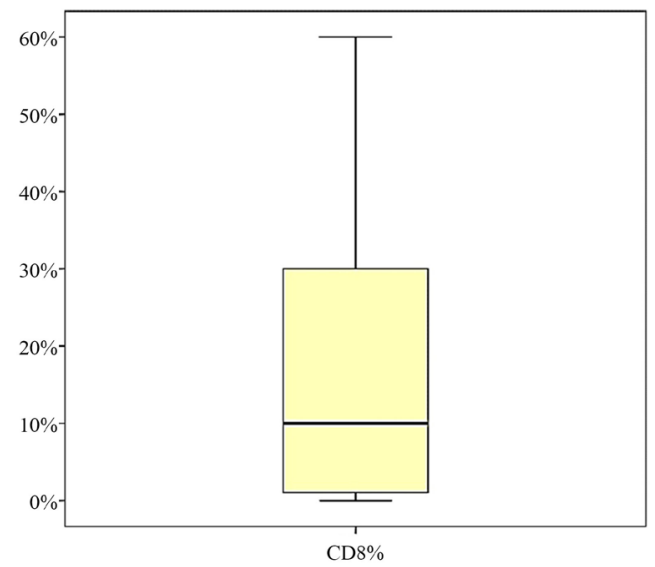

(b)

Figure 2. IQR for presence of (a) CD4 and (b) CD8 in all cohort. 
Table 1. Tumor pathological characteristics.

\begin{tabular}{|c|c|c|}
\hline Tumor Characteristics & n. & $\%$ \\
\hline \multicolumn{3}{|l|}{ Pathological types } \\
\hline Invasive duct carcinoma & 44 & 97.0 \\
\hline Medullary carcinoma & 1 & 3.0 \\
\hline \multicolumn{3}{|l|}{ Grade } \\
\hline Grade I & 0 & 0 \\
\hline Grade II & 38 & 84.4 \\
\hline Grade III & 7 & 15.5 \\
\hline \multicolumn{3}{|l|}{ Lymph node positivity } \\
\hline Positive & 39 & 86.6 \\
\hline Negative & 6 & 13.3 \\
\hline \multicolumn{3}{|l|}{ Tumor size } \\
\hline $\mathrm{T} 1$ & 0 & 0 \\
\hline $\mathrm{T} 2$ & 26 & 57.7 \\
\hline $\mathrm{T} 3$ & 7 & 15.5 \\
\hline $\mathrm{T} 4$ & 12 & 26.6 \\
\hline \multicolumn{3}{|l|}{ Tumor number } \\
\hline Single & 32 & 71.0 \\
\hline Multifocal & 13 & 28.8 \\
\hline \multicolumn{3}{|l|}{ Estrogen receptors } \\
\hline Positive & 27 & 60.0 \\
\hline Negative & 18 & 40.0 \\
\hline \multicolumn{3}{|l|}{ Progesterone receptors } \\
\hline Positive & 23 & 51.1 \\
\hline Negative & 22 & 48.8 \\
\hline \multicolumn{3}{|l|}{ HER 2 receptors } \\
\hline Positive & 20 & 55.5 \\
\hline Negative & 25 & 44.5 \\
\hline \multicolumn{3}{|l|}{ KI67 } \\
\hline$>20 \%$ & 10 & 22.2 \\
\hline$<20 \%$ & 35 & 77.7 \\
\hline \multicolumn{3}{|l|}{ Molecular subtypes } \\
\hline Luminal A & 4 & 8.8 \\
\hline Luminal B & 23 & 51.1 \\
\hline Her2 & 10 & 22.2 \\
\hline Triple negative & 8 & 17.7 \\
\hline
\end{tabular}

\section{TILs and clinico-pathological parameters:}

A significant difference in estrogen receptor status and molecular subtype was evident between both CD4 high and low groups. In CD4 groups, the ER positive cases represented $69.7 \%$ and $33.3 \%$ of cases included in CD4 low and CD4 high groups respectively $(\mathrm{p}=0.029)$. Patients with Her2 enriched subtype showed higher CD4 expression when compared with other molecular subtypes $(\mathrm{p}=$ 
0.007). On the other hand, the molecular subtype expressed a significant correlation with CD8 among other parameters $(\mathrm{p}=0.018)$; with Her2 subtype showing the highest CD8 expression (Table 2) (Figure 3).

Table 2. Correlation between TILs and clinico-pathological parameters.

\begin{tabular}{|c|c|c|c|c|c|c|}
\hline & \multicolumn{2}{|c|}{$\mathrm{CD} 4(\mathrm{~N})$} & \multirow[t]{2}{*}{$\mathrm{p}$ Value } & \multicolumn{2}{|c|}{ CD8 (N) } & \multirow[b]{2}{*}{$\mathrm{p}$ Value } \\
\hline & $\begin{array}{l}\text { Low CD4 } \\
0 \%-29 \%\end{array}$ & $\begin{array}{c}\text { High CD4 } \\
30 \%-100 \%\end{array}$ & & $\begin{array}{l}\text { Low CD8 } \\
0 \%-29 \%\end{array}$ & $\begin{array}{c}\text { High CD8 } \\
30 \%-100 \%\end{array}$ & \\
\hline \multicolumn{7}{|l|}{ Menopausal Status } \\
\hline $\begin{array}{l}\text { Premenopausal } \\
\text { postmenopausal }\end{array}$ & $\begin{array}{l}13 \\
20\end{array}$ & $\begin{array}{l}8 \\
4\end{array}$ & 0.1 & $\begin{array}{l}14 \\
19\end{array}$ & $\begin{array}{l}7 \\
5\end{array}$ & 0.35 \\
\hline \multicolumn{7}{|c|}{ Pathological Subtype } \\
\hline $\begin{array}{c}\text { IDC } \\
\text { Others }\end{array}$ & $\begin{array}{l}32 \\
1\end{array}$ & $\begin{array}{c}12 \\
0\end{array}$ & 0.54 & $\begin{array}{c}32 \\
1\end{array}$ & $\begin{array}{c}12 \\
0\end{array}$ & 0.54 \\
\hline \multicolumn{7}{|l|}{ Grade } \\
\hline $\begin{array}{l}\text { GII } \\
\text { GIII }\end{array}$ & $\begin{array}{c}28 \\
5\end{array}$ & $\begin{array}{c}10 \\
2\end{array}$ & 0.9 & $\begin{array}{c}28 \\
5\end{array}$ & $\begin{array}{c}10 \\
2\end{array}$ & 0.9 \\
\hline \multicolumn{7}{|l|}{ Molecular Subtype } \\
\hline Luminal A & 4 & 0 & \multirow{3}{*}{0.007} & 4 & 0 & \multirow{3}{*}{0.018} \\
\hline $\begin{array}{c}\text { Luminal B } \\
\text { TNBC }\end{array}$ & $\begin{array}{l}19 \\
6\end{array}$ & $\begin{array}{l}4 \\
2\end{array}$ & & $\begin{array}{l}18 \\
7\end{array}$ & $\begin{array}{l}5 \\
1\end{array}$ & \\
\hline Her-2 & 4 & 6 & & 4 & 6 & \\
\hline \multicolumn{7}{|l|}{ Estrogen Receptor } \\
\hline $\begin{array}{l}\text { Positive } \\
\text { Negative }\end{array}$ & $\begin{array}{l}23 \\
10\end{array}$ & $\begin{array}{l}4 \\
8\end{array}$ & 0.029 & $\begin{array}{l}22 \\
11\end{array}$ & $\begin{array}{l}5 \\
7\end{array}$ & 0.13 \\
\hline \multicolumn{7}{|l|}{$\begin{array}{c}\text { Progesterone } \\
\text { Receptor }\end{array}$} \\
\hline $\begin{array}{l}\text { Positive } \\
\text { Negative }\end{array}$ & $\begin{array}{l}19 \\
14\end{array}$ & $\begin{array}{l}4 \\
8\end{array}$ & 0.15 & $\begin{array}{l}18 \\
15\end{array}$ & $\begin{array}{l}5 \\
7\end{array}$ & 0.45 \\
\hline \multicolumn{7}{|l|}{ Ki67\% } \\
\hline $\begin{array}{l}<20 \\
\geq 20\end{array}$ & $\begin{array}{l}7 \\
26\end{array}$ & $\begin{array}{l}3 \\
9\end{array}$ & 0.78 & $\begin{array}{c}8 \\
25\end{array}$ & $\begin{array}{c}2 \\
10\end{array}$ & 0.59 \\
\hline \multicolumn{7}{|c|}{ Her-2 overexpression } \\
\hline $\begin{array}{l}\text { Positive } \\
\text { Negative }\end{array}$ & $\begin{array}{l}13 \\
20\end{array}$ & $\begin{array}{l}7 \\
5\end{array}$ & 0.26 & $\begin{array}{l}13 \\
20\end{array}$ & $\begin{array}{l}7 \\
5\end{array}$ & 0.26 \\
\hline \multicolumn{7}{|l|}{ Stage } \\
\hline $\mathrm{T} 2$ & 17 & 9 & \multirow{3}{*}{0.20} & 18 & 8 & \multirow{3}{*}{0.38} \\
\hline $\mathrm{T} 3$ & 6 & 1 & & 5 & 2 & \\
\hline $\mathrm{T} 4$ & 10 & 2 & & 10 & 2 & \\
\hline \multicolumn{7}{|l|}{ Nodal status } \\
\hline $\begin{array}{l}\text { Positive } \\
\text { Negative }\end{array}$ & $\begin{array}{c}28 \\
5\end{array}$ & $\begin{array}{l}11 \\
1\end{array}$ & 0.55 & $\begin{array}{c}28 \\
5\end{array}$ & $\begin{array}{c}11 \\
1\end{array}$ & 0.55 \\
\hline
\end{tabular}




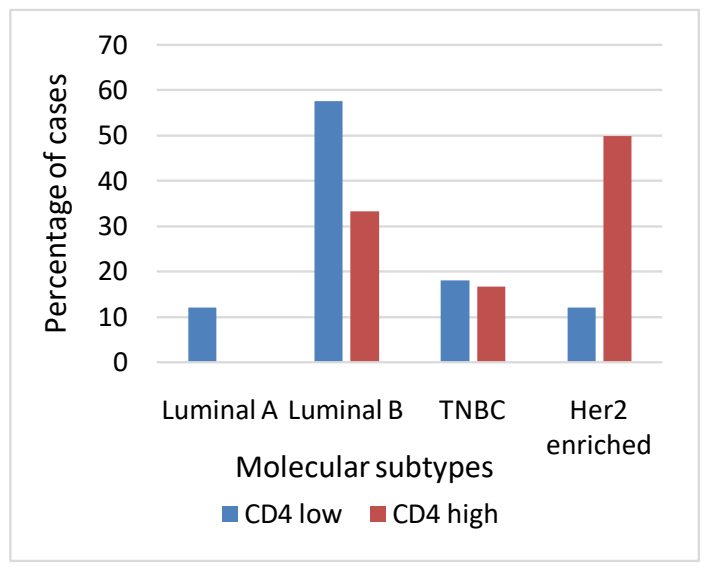

(a)

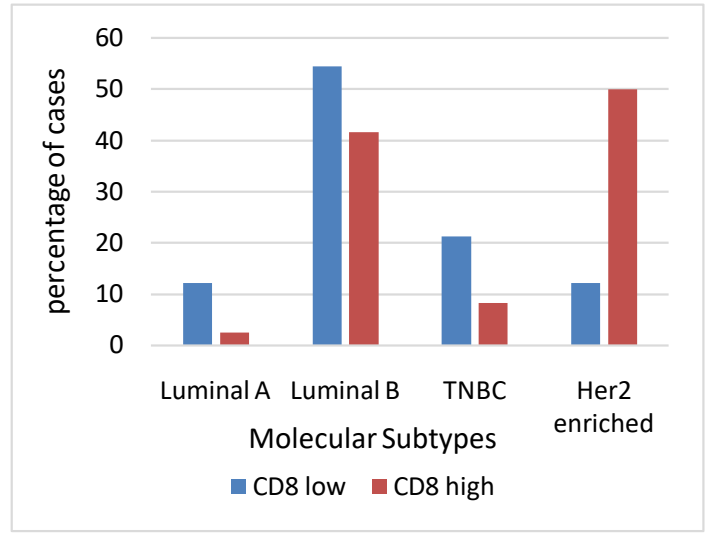

(b)

Figure 3. Correlation between molecular subtypes and TILs levels (a) CD4 low and high groups (b) CD8 low and high groups.

\section{Prognostic value of TILs:}

High CD4 group showed significantly increased pCR in comparison to low CD4 (17.7\% and $11.1 \%$ respectively) $(\mathrm{p}=0.003)$. All patients in high CD4 group developed either $\mathrm{pCR}$ or partial remission but no patient experienced stationary disease or progression after neoadjuvant chemotherapy. With regards to pCR among different molecular subtypes, 10 tumors (76.9\%) were Her2 positive, 2 (15.3\%) were TNBC and 1 (7.6\%) was luminal B.

In this analysis, we found that the correlation between $\mathrm{pCR}$ and presence of CD4 was nonlinear. Rates of PCR increased when levels of CD4 were greater than $3 \%$ (Figure 4 ).

In our cohort $25(55.6 \%)$ patients showed residual tumors after neoadjuvant chemotherapy and surgery. High CD4 group developed significantly smaller residual tumors in comparison to CD4 low group $(\mathrm{p}=0.04)$.

At a median follow-up of 24 months (7 - 26), Patients with a baseline CD4 of at least 30\% showed higher 2-years DFS (95\% CI, $18.6-22.9, \mathrm{p}=0.04)$ regardless of pCR outcome. Of note, in patients with $\geq 30 \%$ CD4 levels, 8 of 12 (66.6\%) achieved a pCR (Figure 5). 


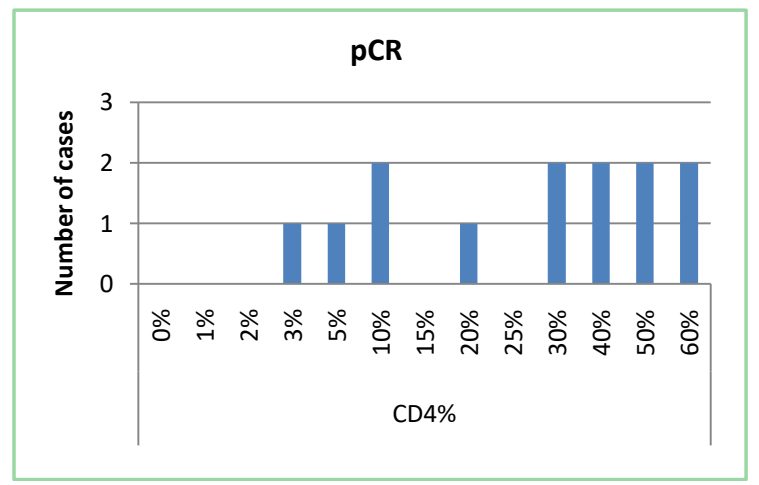

Figure 4. Correlation between pCR and CD4 percentage.

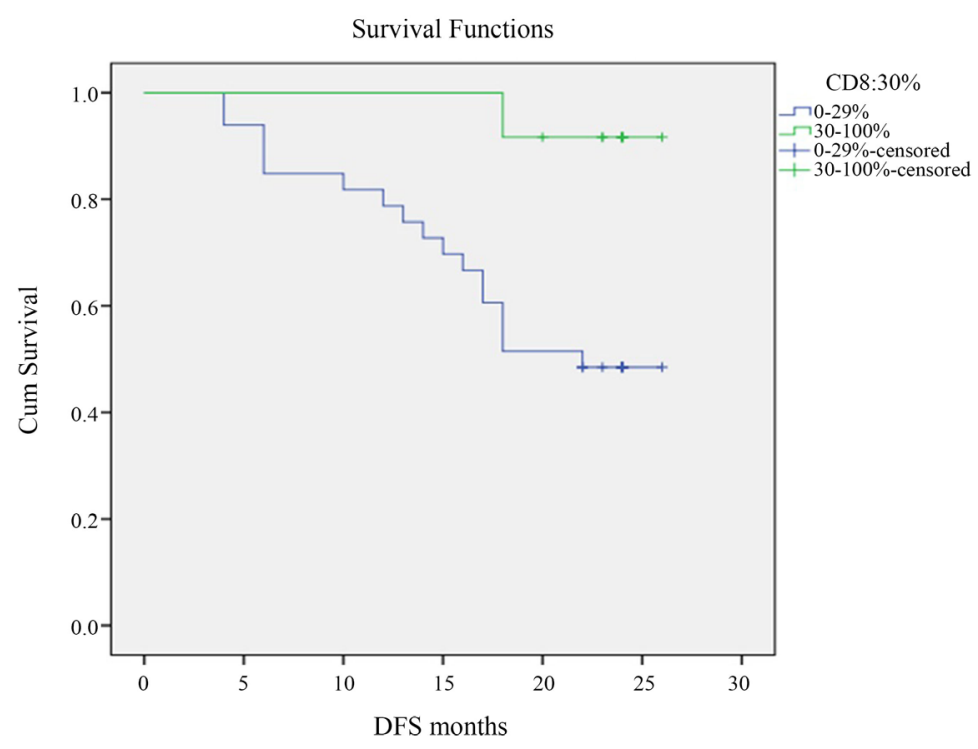

(a)

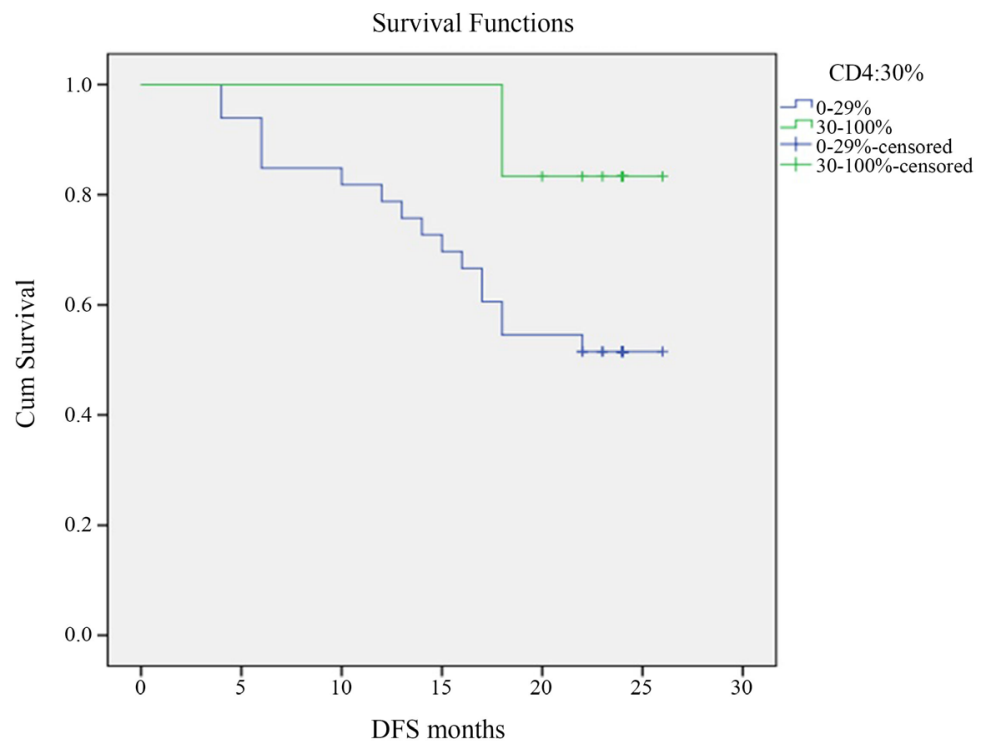

(b)

Figure 5. DFS curve according to (a) high and low CD4 and (b) high and low CD8. 
By the end of the study 38 patients were still alive with 7 deaths occurring in low $\mathrm{CD} 4$ group while no deaths were seen in high CD4 group $(\mathrm{p}=0.09)$.

Data regarding CD8 showed some differences as compared to CD4. High CD8 significantly improved the DFS (95\% CI, $18.6-22.9 ; \mathrm{p}=0.01)$. Also, High CD8 group showed a significant association with smaller residual tumors $(p=0.003)$, but there was no significant difference regarding $\mathrm{pCR}$ or OS between $\mathrm{CD} 8$ high and low groups (Table 3 ).

\section{TILs and pattern of treatment failure:}

After neoadjuvant chemotherapy and radical surgery, $40 \%$ patients developed events in the form of local recurrence or distant metastasis. In CD4 low group, 2 patients developed local recurrence and 14 patients had distant metastasis while in CD4 high group only one patient had local recurrence and distant metastasis $(\mathrm{p}=0.19)$. Similarly, in CD8 low group 2 patients had local recurrence and 15 patients developed distant metastasis while in CD8 high group, one patient had local recurrence only $(\mathrm{p}=0.025)$ (Table 3$)$.

\section{Discussion}

The understanding of tumor immune microenvironment influences the development of immunotherapy, it also affects the tumor response to other anticancer drugs and treatment outcomes [19] [20].

Recently, TILs proved to play a promising role as predictors of response to neoadjuvant chemotherapy in breast cancer. This opens new opportunities for different treatment plans, based on modulation of immune responses [21] [22] [23].

In the current trial we investigated the correlation between TILs and the response to neoadjuvant chemotherapy in locally advanced breast cancer cases in Egyptian females. We classified TILs into two distinct groups (high and low) based on the interquartile range of stromal TILs levels. The IQR was equal in both $\mathrm{CD} 4$ and $\mathrm{CD} 8$ with significant results regarding its prognostic and predictive value.

In our study, the cut off between TILs high and low groups was 30\%, this value allowed for a significant correlation between TILs and different prognostic indicators. Other reports employed different cut off points for this purpose such as $35 \%$ cut off in a study by Kotoula et al., in 2016, while Jang and colleagues reported $10 \%$ cut off value to define TILs levels that were associated with better outcomes for a subset of hormone positive breast cancer patients [24] [25].

Table 3. TILs evaluation in relation to residual tumors and failure of treatment.

\begin{tabular}{|c|c|c|c|c|c|c|}
\hline \multirow[b]{2}{*}{ Groups } & \multicolumn{3}{|c|}{ Residual Tumors } & \multicolumn{3}{|c|}{ Patterns of treatment failure } \\
\hline & Residual tumor $<2 \mathrm{~cm}$ & Residual tumor $\geq 2 \mathrm{~cm}$ & $\mathrm{p}$ Value & Local recurrence & Distant metastasis & $\mathrm{p}$ Value \\
\hline \multicolumn{7}{|l|}{ CD4: } \\
\hline Low $(0 \%-29 \%)$ & 9 & 12 & 0.04 & 2 & 14 & 0.19 \\
\hline High (30\% - 100\%) & 4 & 0 & & 1 & 1 & \\
\hline \multicolumn{7}{|l|}{ CD8: } \\
\hline Low $(0 \%-29 \%)$ & 6 & 7 & 0.003 & 2 & 15 & 0.025 \\
\hline High $(30 \%-100 \%$ & 7 & 0 & & 1 & 0 & \\
\hline
\end{tabular}


Herrero-Vicent et al. in their trial reported that Lymphocyte predominant breast cancer (LPBC) group achieved significantly higher PCR rates than non-LPBC. TILs (high and low levels) proved to have significant prognostic value regarding disease free survival. Median DFS in non-LPBC was 20 months and LPBC was 97 months [26]. Similar data were reported by the NeoALLTO trial, as a nonlinear relationship was seen between pCR and presence of TILs, rates of PCR increased sharply when levels of stromal TILs were greater than 5\%, regardless of treatment [27]. These reports are comparable to our results as the high CD4 group in this cohort showed increased rates of $\mathrm{pCR}$ in contrast to low CD4 group $(17.7 \%$ vs. $11.1 \% \mathrm{p}=0.003)$, rates of $\mathrm{pCR}$ increased when CD4 was greater than 3\%. Baseline CD4 of at least 30\% showed higher 2-years DFS (95\% CI, [18.6 - 22.9]; $\mathrm{p}=0.04)$ regardless of $\mathrm{pCR}$ outcome.

TILs are proven to be predictive of response to neoadjuvant chemotherapy in hormone negative breast cancers [28] [29] [30]. In PREDICT trial; multiple clinical and pathological parameters correlated with high TILs including hormone negative tumors, higher tumor grade, ductal carcinoma vs lobular carcinoma and node negative vs nodes positive. This data is in agreement with our cohort, as the estrogen receptor status and molecular subtypes revealed significant differences regarding their CD4 expression levels $(\mathrm{p}=0.02)$. In luminal A group no patients had high CD4 or CD8 ( $\geq 30 \%)$, HER2 subtype showed significantly higher CD4 $(\mathrm{p}=0.007)$ and CD8 $(\mathrm{p}=0.02)$ levels when compared with other molecular subtypes. The NeoALTTO trial also showed comparable results, where the IQR level of TILs was $12.5 \%$, with levels lower in hormone receptor-positive in comparison to hormone receptor-negative tumors [27] [31].

At a median follow-up of 3 years, Herrero-Vicent et al. observed that recurrence rates in LPBC was $2 \%$ while the rate was significantly higher in non-LPBC group (30\%) [26]. Similarly, we reported higher recurrence rate in TIL low group as compared to TIL high groups for both CD4 and CD8, however, statistical significance was evident in CD8 groups only $(\mathrm{p}=0.02)$.

Recently, the guidelines of the Immuno-Oncology Biomarker Working Group have contributed to reproducibility of TILs evaluation in residual disease as TILs in the post-neoadjuvant residual disease setting are obtaining rising interest [15]. One of the limitations of our cohort was the small number of cases with residual disease. However, we elucidated a significant correlation between high TILs levels and smaller residual tumor. Another limitation of the study was the lack of TILs evaluation within in-situ carcinoma settings.

\section{Conclusion}

We concluded that presence of high TILs levels may identify a group of patients with excellent prognosis (achieved pCR after NAC). Nevertheless, we raise the concerns to find mutual agreement regarding a standard cut off point to define high and low TIL levels as the heterogeneity in different studies may be due to interobserver variability in TILs assessment. Further large-scale clinical studies 
may address such elusive issues and reach a consensus regarding the utility of TILs in combination with other morphological or genomics-based parameters to stratify patients of breast cancer after the use of NAC.

\section{Funding}

This research did not receive any specific grant from funding agencies in the public, commercial, or not-for-profit sectors.

\section{Conflicts of Interest}

The authors declare no conflicts of interest regarding the publication of this paper.

\section{References}

[1] Mamounas, E.P. (2015) Impact of Neoadjuvant Chemotherapy on Locoregional Surgical Treatment of Breast Cancer. Annals of Surgical Oncology, 22, 1425-1433. https://doi.org/10.1245/s10434-015-4406-6

[2] Sasanpour, P., Sandoughdaran, S., Mosavi-Jarrahi, A. and Malekzadeh, M. (2018) Predictors of Pathological Complete Response to Neoadjuvant Chemotherapy in Iranian Breast Cancer Patients. Asian Pacific Journal of Cancer Prevention, 19, 2423-2427.

[3] Pruneri, G., Vingiani, A. and Denkert, C. (2017) Tumor Infiltrating Lymphocytes in Early Breast Cancer. Breast, 37, 207-214. https://doi.org/10.1016/j.breast.2017.03.010

[4] Asano, Y., Kashiwagi, S., Goto, W., Takada, K., Takahashi, K., Hatano, T., et al. (2018) Prediction of Treatment Response to Neoadjuvant Chemotherapy in Breast Cancer by Subtype Using Tumor-Infiltrating Lymphocytes. Anticancer Research, 38, 2311-2321. https://doi.org/10.21873/anticanres.12476

[5] Dushyanthen, S., Beavis, P.A., Savas, P., Teo, Z.L., Zhou, C., Mansour, M., et al. (2015) Relevance of Tumor-Infiltrating Lymphocytes in Breast Cancer. BMC Medicine, 13, 202. https://doi.org/10.1186/s12916-015-0431-3

[6] Heppner, B., Loibl, S. and Denkert, C. (2016) Tumor-Infiltrating Lymphocytes: A Promising Biomarker in Breast Cancer. Breast Care, 11, 96-100. https://doi.org/10.1159/000444357

[7] Pardoll, D.M. (2012) The Blockade of Immune Checkpoints in Cancer Immunotherapy. Nature Reviews Cancer, 12, 252-264. https://doi.org/10.1038/nrc3239

[8] Denkert, C., Loibl, S., Noske, A., Roller, M., Müller, B.M., Komor, M., et al. (2010) Tumor-Associated Lymphocytes as an Independent Predictor of Response to Neoadjuvant Chemotherapy in Breast Cancer. Journal of Clinical Oncology. Official Journal of the American Society of Clinical Oncology, 28, 105-113. https://doi.org/10.1038/nrc3239

[9] Apetoh, L., Ghiringhelli, F., Tesniere, A., Obeid, M., Ortiz, C., Criollo, A., et al. (2007) Toll-Like Receptor 4-Dependent Contribution of the Immune System to Anticancer Chemotherapy and Radiotherapy. Nature Medicine, 13, 1050-1059. https://doi.org/10.1038/nm1622

[10] Mattarollo, S.R., Loi, S., Duret, H., Ma, Y., Zitvogel, L. and Smyth, M.J. (2011) Pivotal Role of Innate and Adaptive Immunity in Anthracycline Chemotherapy of Established Tumors. Cancer Research, 71, 4809-4820. 
https://doi.org/10.1158/0008-5472.CAN-11-0753

[11] Andre, F., Dieci, M.V., Dubsky, P., Sotiriou, C., Curigliano, G., Denkert, C., et al. (2013) Molecular Pathways: Involvement of Immune Pathways in the Therapeutic Response and Outcome in Breast Cancer. Clinical Cancer Research, 19, 28-33. https://doi.org/10.1158/1078-0432.CCR-11-2701

[12] Cimino-Mathews, A., Foote, J.B. and Emens, L.A. (2015) Immune Targeting in Breast Cancer. Oncology, 29, 375-385.

[13] Bianchini, G., Qi, Y., Alvarez, R.H., Iwamoto, T., Coutant, C., Ibrahim, N.K., et al. (2010) Molecular Anatomy of Breast Cancer Stroma and Its Prognostic Value in Estrogen Receptor-Positive and -Negative Cancers. Journal of Clinical Oncology, 28, 4316-4323. https://doi.org/10.1200/JCO.2009.27.2419

[14] Sahoo, S. and Leste, S.C. (2019) Pathology of Breast Carcinomas after Neoadjuvant Chemotherapy. An Overview with Recommendations on Specimen Processing and Reporting. Archives of Pathology \& Laboratory Medicine, 133, 633-642.

[15] Hendry, S., Salgado, R., Gevaert, T., Russell, P.A., John, T., Thapa, B., et al. (2017) Assessing Tumor Infiltrating Lymphocytes in Solid Tumors: A Practical Review for Pathologists and Proposal for a Standardized Method from the International Immuno-Oncology Biomarkers Working Group: Part 1: Assessing the Host Immune Response, TILs in Invasive Breast Carcinoma and Ductal Carcinoma in Situ, Metastatic Tumor Deposits and Areas for Further Research. Advances in Anatomic Pathology, 24, 235-251.

[16] Pelekanou, V., Carvajal-Hausdorf, D.E., Altan, M., Wasserman, B., Carvajal-Hausdorf, C., Wimberly, H., et al. (2017) Effect of Neoadjuvant Chemotherapy on Tumor-Infiltrating Lymphocytes and PD-L1 Expression in Breast Cancer and Its Clinical Significance. Breast Cancer Research, 19, 1-11.

https://doi.org/10.1186/s13058-017-0898-2

[17] Mao, Y., Qu, Q., Zhang, Y., Liu, J., Chen, X. and Shen, K. (2014) The Value of Tumor Infiltrating Lymphocytes (TILs) for Predicting Response to Neoadjuvant Chemotherapy in Breast Cancer: A Systematic Review and Meta-Analysis. PLoS ONE, 9, e115103. https://doi.org/10.1371/journal.pone.0115103

[18] Kashiwagi, S., Asano, Y., Goto, W., Takada, K., Takahashi, K., Hatano, T., et al. (2017) Using TILs to Predict Therapeutic Effect of Chemotherapy (Pertuzumab, Trastuzumab, Docetaxel) on HER2-Positive Breast Cancer. Anticancer Research, 37, 5623-5630. https://doi.org/10.21873/anticanres.11997

[19] Zitvogel, L., Kepp, O. and Kroemer, G. (2011) Immune Parameters Affecting the Efficacy of Chemotherapeutic Regimens. Nature Reviews Clinical Oncology, 8, 151-160. https://doi.org/10.1038/nrclinonc.2010.223

[20] Dougan, M. and Dranoff, G. (2009) Immune Therapy for Cancer. Annual Review of Immunology, 27, 83-117. https://doi.org/10.1146/annurev.immunol.021908.132544

[21] Criscitiello, C., Esposito, A., Trapani, D. and Curigliano, G. (2016) Prognostic and Predictive Value of Tumor Infiltrating Lymphocytes in Early Breast Cancer. Cancer Treatment Reviews, 50, 205-207. https://doi.org/10.1016/j.ctrv.2016.09.019

[22] Tang, H., Qiao, J. and Fu, Y.X. (2016) Immunotherapy and Tumor Microenvironment. Cancer Letters, 370, 85-90. https://doi.org/10.1016/j.canlet.2015.10.009

[23] Taube, J.M., Galon, J., Sholl, L.M., Rodig, S.J., Cottrell, T.R., Giraldo, N.A., et al. (2018) Implications of the Tumor Immune Microenvironment for Staging and Therapeutics. Modern Pathology, 31, 214-234. https://doi.org/10.1038/modpathol.2017.156

[24] Kotoula, V., Chatzopoulos, K., Lakis, S., Alexopoulou, Z., Timotheadou, E., 
Zagouri, F., et al. (2016) Tumors with High-Density Tumor Infiltrating Lymphocytes Constitute a Favorable Entity in Breast Cancer: A Pooled Analysis of Four Prospective Adjuvant Trials. Oncotarget, 7, 5074-5087. https://doi.org/10.18632/oncotarget.6231

[25] Jang N, Kwon HJ, Park MH, Kang SH and Bae YK (2018) Prognostic Value of Tumor-Infiltrating Lymphocyte Density Assessed Using a Standardized Method Based on Molecular Subtypes and Adjuvant Chemotherapy in Invasive Breast Cancer. Annals of Surgical Oncology, 25, 937-946.

https://doi.org/10.1245/s10434-017-6332-2

[26] Herrero-Vicent, C., Guerrero, A., Gavilá, J., Gozalbo, F., Hernández, A., Sandiego, S., et al. (2017) Predictive and Prognostic Impact of Tumor-Infiltrating Lymphocytes in Triple-Negative Breast Cancer Treated with Neoadjuvant Chemotherapy. Cancer, 11, 759. https://doi.org/10.3332/ecancer.2017.759

[27] Salgado, R., Denkert, C., Campbell, C., Savas, P., Nuciforo, P., Aura, C., et al. (2015) Tumor-Infiltrating Lymphocytes and Associations with Pathological Complete Response and Event-Free Survival in HER2-Positive Early Stage Breast Cancer Treated with Lapatinib and Trastuzumab. JAMA Oncology, 1, 448-454.

https://doi.org/10.1001/jamaoncol.2015.0830

[28] Denkert, C., von Minckwitz, G., Brase, J.C., Sinn, B.V., Gade, S., Kronenwett, R., et al. (2015) Tumor-Infiltrating Lymphocytes and Response to Neoadjuvant Chemotherapy with or without Carboplatin in Human Epidermal Growth Factor Receptor 2-Positive and Triple-Negative Primary Breast Cancers. Journal of Clinical Oncology, 33, 983-991. https://doi.org/10.1200/JCO.2014.58.1967

[29] Loi, S., Sirtaine, N., Piette, F., Salgado, R., Viale, G., Van Eenoo, F., et al. (2013) Prognostic and Predictive Value of Tumor-Infiltrating Lymphocytes in a Phase III Randomized Adjuvant Breast Cancer Trial in Node-Positive Breast Cancer Comparing the Addition of Docetaxel to Doxorubicin with Doxorubicin-Based Chemotherapy: BIG 02-98. Journal of Clinical Oncology, 31, 860-867. https://doi.org/10.1200/JCO.2011.41.0902

[30] Loi, S., Michiels, S., Salgado, R., Sirtaine, N., Jose, V., Fumagalli, D., et al. (2014) Tumor-Infiltrating Lymphocytes Are Prognostic in Triple Negative Breast Cancer and Predictive for Trastuzumab Benefit in Early Breast Cancer: Results from the FinHER Trial. Annals of Oncology, 25, 1544-1550.

https://doi.org/10.1093/annonc/mdu112

[31] Issa-Nummer, Y., Darb-Esfahani, S., Loibl, S., Nekljudova, V., Schrader, I., Sinn, B.V., et al. (2013) Prospective Validation of Immunological Infiltrate for Prediction of Response to Neoadjuvant Chemotherapy in HER2-Negative Breast Cancer: A Substudy of the Neoadjuvant GeparQuinto Trial. PLOS ONE, 8, e79775.

https://doi.org/10.1371/journal.pone.0079775 